\title{
Influence of Sunshine Hour and Relative Humidity on Total Solar Radiation at Nepalganj, Nepal
}

\author{
Joshi Usha Joshi, Shrestha P.M., Karki I.B., Chapagain N.P., \& Poudyal K.N.
}

\begin{abstract}
:
The solar energy is the abundantly available free and clean energy resources in Nepal. There are more than 300 sunny days because of Nepal lies in solar zone in a global map. The total solar radiation was measured by using CMP6 pyranometer at Nepalgunj(lat.: 28.10 ${ }^{\circ} \mathrm{N}$, long.: $81.67^{\circ}$ Eand Alt. 165.0masl). The main objective of this study is to select thebetter empirical model and its empirical constants for the prediction of TSR for the year come. In this research, six different empirical models and meteorological parameters are utilized in the presence of regression technique for the years 2011 and 2012. Finally the different empirical constants are found. After the error analysis, the Swarthman-Oguniade model is found to perform better than others models. So the empirical constants of this model is utilized to predict theTSR of similar geographical sites of Nepal.
\end{abstract}

Keywords: Total Solar Radiation,meteorological parameters, empirical models, Regression technique,EmpiricalConstants.

\section{Introduction}

Solar energy is one of the most important and promising renewable resources and sustainable energy. In additionthat it is clean and green energy. All the form of energy on the earth are derived from the sun.Most of the solar energy received in the form of radiation(Iqbal,1983). Almost all radiated energy entering the earth atmosphere comes from the sun. This radiation covers the entire electromagnetic spectrum from gamma ray \& X-ray, through ultra-violet, visible and infra-red radiation to microwave \& radio waves. Out of solar radiation reaching the earth surface, $99 \%$ has wavelength between $(150-400 \mathrm{~nm})$, with $9 \%$ in ultra-violet $(<400 \mathrm{~nm}), 49 \%$ in visible $(400<<700 \mathrm{~nm})$ and $42 \%$ in the infrared $(>700 \mathrm{~nm})$ (Iqbal, 1983; Sekar et al., 2012).

Energy is joined by intrinsic bonding with environment, social \& economical dimension of sustainable development(Poudyal et al., 2013). The demand of energy is increasing vigorously worldwide which is followed by the consumption of fossil fuels and increasing pollution level. It is also observed that energy consumption in the house hold sector is perhaps the single largest consumer of energy in the nation's economy in the developing countries like Nepal enforcing rapid consumption of fossil fuel reserves resulting in speedy depletion. So it is unevitable that the world will soon run out of its energy resources (Genwa \& Anju, 2012; Li et al., 2010). In developing countries whose economy heavily depends on 
imported products, it is highly desirable that alternateenergy resources should be utilized with maximum conversion efficiency (Poudyal, 2017).

There are several types of empirical formula for estimation of daily mean hourly total solar radiation as a function of meteorological parameters(Iqbal, 1983; Sayigh, 1977; Klein, 1977).The total solar radiation varies from latitude to latitude and season to season.Thus solar radiation is obtained and calculate the ratio of the actual number of hours of sunshine received at a site to the day length (Iqbal, 1979; Sears et al., 1981). The amount of total solar radiation $H_{o}$, is extra-terrestrial radiation which is found above the atmosphere. Similarly, $H_{g}$ is the measured total solar radiationwhich is the fraction of the extraterrestrial solar radiation on the ground surface after scattering, reflection and absorption in the atmosphere. The ratio of $H_{g} / H_{\odot}$ is coefficient of transmission or clearness index (Babatunde \& Aro, 1990).

This research paper focuses on the impact of meteorological parameters in TSR on the basis of linear regression technique, used to develop some predictive model classified as sunshine hours and relative humidity for estimation of total solar radiation at low land of Nepal.

\section{Measuring Site}

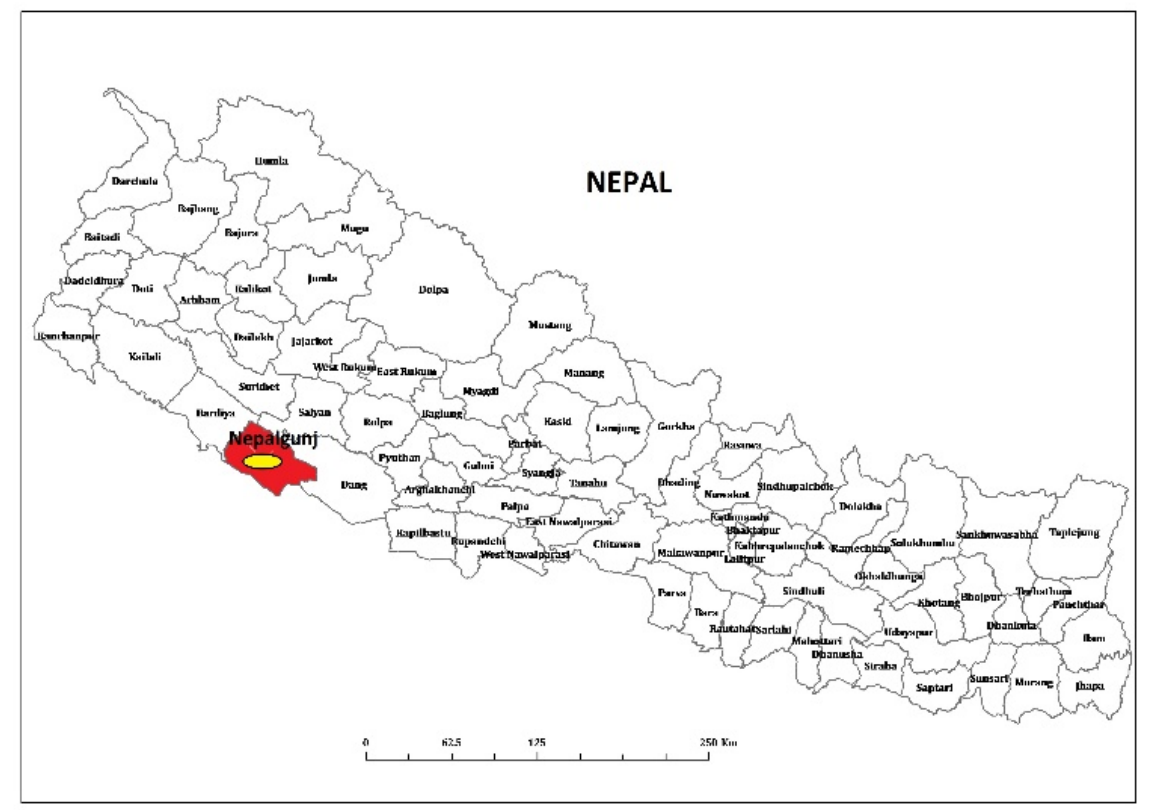

Fig. 1: Map of Nepal

Nepalgunj(lat.: $28.10^{\circ} \mathrm{N}$, long.: $81.67^{\circ} \mathrm{E}$ and Alt. 165.0 masl) is located at mid-western part of Nepal at providence No. 5, in Banke district, Bheri zone (Wikipedia contributors, 2020b). Banke is bordered on the west by Bardiya district. Nepalgunj, Sub-Metropolitan city covers 
an area of $85.94 \mathrm{~km}^{2}$. Its population is 73,779 and density is $1616.74 / \mathrm{sqkm}$ (Wikipedia contributors, 2020b).

Nepalgunj has a sub-tropical climate. The highest temperature recorded in Nepalgunj was $45.0{ }^{\circ} \mathrm{C}$ on 16 June 1995 on summer season, while the minimum temperature recorded was $-0.3{ }^{\circ} \mathrm{C}$ on 9 January 2013 , on winter. The rainy season starts in June and lasting into September, it is less hot and very humid. The sunny day of winter is usually pleasant. It sometimes is foggy and overcast with temperatures below $10^{\circ} \mathrm{C}$.

\section{Methods and Instrumentation}

The daily data of total solar radiation, sunshine hours, relative humidity and rainfall on horizontal surface were collected from Department of Hydrology andMeteorology (DHM), Government of Nepal. The total radiation of horizontal surface was measured by using Kipp and Zonen CMP6 Pyranometer.

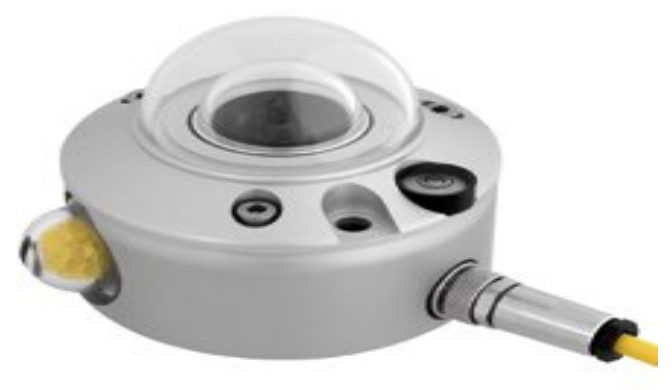

Fig.2:CMP6 Pyranometer

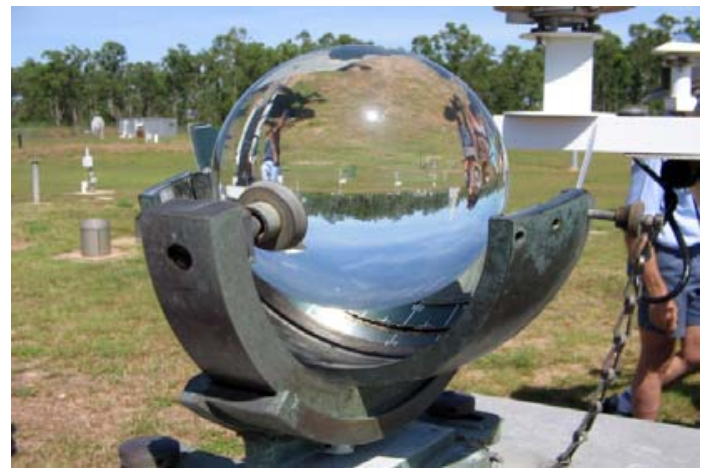

Fig. 3: Campbell stokes sunshine recorder

The CMP6 Pyranometer consists of black surface and gets heated exposed to the solar radiation then we get global solar radiation in the form of $\mathrm{W} / \mathrm{m}^{2}$. This typical pyronometr has wide spectral range of instrument from $280 \mathrm{~nm}$ to $2800 \mathrm{~nm}$. The operating temperature is from $-40^{\circ} \mathrm{C}$ to $80^{\circ} \mathrm{C}$. The sensitivity of instrument and field of view are 5 to $15 \mu \mathrm{V} / \mathrm{W} / \mathrm{m}^{2}$ and 1800 respectively. The special features of this instrument are low noise high resolution and low power consumption. It works in all weather conditions which collects the data at real time for needs of Meteorological parameter("Manual", 2008).

The sunshine hours is measured by the instrument Campbell stokes sunshine recorder (Stanhill,

2003). It is like a glass sphere that focuses sun rays on the strip of card board. The Campbell sunshine recorder is self-recording instrument where heat of the sun is used as recording medium the instrument has the base plate,stand support for the sphere attached metal and massive glass plate. The inner sides of bowl consists of cads which are concentric to the glass sphere. The rays from the sun are focused by glass sphere to an intense spot. As the 
earth rotates, the position of the spot moves across the card. When sun is eclipsed then the trace gets interrupted (Wikipedia

contributors, 2020a).

For long time, data of solar radiation has not been sufficient to evaluate magnitude of total solar radiation distribution. Then many methods have been developed as an effort to deduce its value. Among several parameters sunshine hours(n) data is taken as better one which depends on declination angle and of course cloudiness(Sayigh, 1977). We estimate the daily total solar radiation on horizontal surface, using sunshine duration data on Angstrom and Prescott Model. (Angstrom,1924; Prescott, 1940). The modified form of the Angstrom-type equation is,

$\frac{H_{g}}{H_{0}}=a+b \frac{n}{N} \ldots . .(1)$

The six different empirical models based on sunshine hour, relative humidity are given inTable 1, (Li et al., 2010; Besharat et al., 2013; Okundamiya et al., 2016). Where Hg is the daily average hourly total solar radiation on a horizontal surface $\left(\mathrm{MJ} / \mathrm{m}^{2} /\right.$ day $), H_{\text {o }}$ the daily average hourly extraterrestrial total solar radiation on a horizontal surface $\left(\mathrm{MJ} / \mathrm{m}^{2} /\right.$ day $), \mathrm{n}$ the daily average hours of bright sunshine, $\mathrm{N}$ the daily average day length, and "a", "b", "c" and "d" empirical constants are known as Angstrom constants (regression coefficients) and they are empirical (Iqbal, 1979; Duffie \& Beckman, 1991).

Table 1: The six different empirical models and their relations used in research (Besharat et al., 2013; Okundamiya et al., 2016)

\begin{tabular}{|c|c|c|c|}
\hline Model & Symbol & parameters & Relation \\
\hline $\begin{array}{l}\text { Angstrom-Prescott } \\
\text { Model }\end{array}$ & M1 & Ho, n, N & $b\left(\frac{n}{N}\right)$ \\
\hline Oglman et al. Model & M2 & Ho, n, N, & $b \frac{n}{N}+c\left(\frac{n}{N}\right)^{2}$ \\
\hline Samuel Model (1991) & M3 & Ho, n, N, & $a+b \frac{n}{N}+c\left(\frac{n}{N}\right)^{2}+d\left(\frac{n}{N}\right)^{3}$ \\
\hline Bakirci Model (2009) & M4 & $\begin{array}{l}\text { Ho, n, N, } \\
\text { RH }\end{array}$ & $\frac{H_{a}}{H_{o}}=a\left(\frac{n}{N}\right)^{b}$ \\
\hline $\begin{array}{l}\text { Modified Angstrom } \\
\text { Model }\end{array}$ & M5 & & $\frac{H_{q}}{H_{o}}$ \\
\hline $\begin{array}{l}\text { Swarthman-Oguniade } \\
\text { Model }\end{array}$ & M6 & $\begin{array}{l}\text { Ho, n, N, } \\
\text { RH }\end{array}$ & $\frac{H_{q}}{H_{a}}=a+b \frac{n}{N}+c(R H)$ \\
\hline
\end{tabular}

Thus found coefficients $\mathrm{a}, \mathrm{b}, \mathrm{c}$ and $\mathrm{d}$ and meteorological parameters are used in given model to get estimated value of TSR. Then compare the estimated and measured value of TSR and the validation of data is on the basis of statistical parameters like RMSE, MBE, MPE and 
Patan Pragya (Volume: 6, Number: 1 2020)

$\mathrm{R}^{2}$. Finally the better model will be selected on the basis of lower value of RMSE, MBE, MPE and higher value of coefficient of determination.

The values of the extraterrestrial solar radiation $\left(\mathrm{H}_{0}\right)$ can be calculated from the following equation,

$H_{\odot}=\frac{2 \epsilon}{\pi} I_{s e}\left[1+0.033 \cos \left(\frac{46 \omega \pi_{\delta}}{86 \delta}\right)\right]\left[\cos \emptyset \cos \delta \sin \omega+\frac{\pi}{190} \omega \sin \emptyset \sin \delta\right]$

Where $\mathrm{I}_{\mathrm{sc}}$ is the solar constant $\left(=1367 \mathrm{~W} \mathrm{~m}^{-2}\right), \emptyset$ the latitude of the site (rad), the solar declination (rad), the mean sunrise hour angle for the given month, and $\mathrm{n}_{\mathrm{d}}$ the Julian day number of the year starting from the first of January. The solar declination ( ) and the mean sunrise hour angle ( ) can be calculated by the following equations(Duffie \& Beckman, 1991).

$$
\begin{aligned}
& (8 \text { degree })-23.45 \sin \left[\frac{660}{86 \varepsilon}\left(204+n n_{d} \xi\right]\right. \\
& \omega x=\operatorname{coss}^{-1}(-\tan (\tan \Omega)
\end{aligned}
$$

The relation of the day length is

$$
N=\frac{2}{18} \pi=\frac{2}{18} \cos ^{-1}(-\tan \theta \tan \Omega)
$$

The clearness index $\left(\mathrm{K}_{\mathrm{T}}\right)$ as the ratio of the measured horizontal terrestrial solar radiation $\left(H_{g}\right)$, to the extraterrestrial solar radiation $H_{\ominus}$.

\section{Results and discussion}

The empirical constants and statistical errors of various models for Nepalgunj along with the values of coefficient of determination $\left(\mathrm{R}^{2}\right)$ are reported in table 2 . The values of empirical constants $\mathrm{a}, \mathrm{b}, \mathrm{c}$ and $\mathrm{d}$ depend on latitude, sunshine hours, altitude, relative humidity, maximum temperature of air and so on. The sum of these coefficients significantly represent the overall transmission under clear sky condition. According to table 2, it is seen that all the models have statistical significance. The result of coefficient of determination is that its value is higher than $65 \%$, indicating a good fitting between the daily total solar radiation and other meteorological parameters. The value of RMSE is in the range of $2.03-$ $2.35\left(\mathrm{MJ} / \mathrm{m}^{2} /\right.$ day) indicating the fairly good agreement between measured and estimated total solar radiation. The MBE values are in acceptable range in all 6 models. The negative value of MBE in models indicates an underestimation of measured total solar radiation. The mean percentage error of all models are in the range of acceptable values between 2.38\%-1.07\%. Comparing the results obtained from thesesix models, model M6, Swarthman-Oguniade model is found to be more accurate model for prediction of daily total solar radiation on 
Patan Pragya (Volume: 6, Number: 1 2020)

horizontal surface in Nepalgunj than other models. Same model can used to predict the solar radiation in places under similar geographic and climatic conditions.

Table 2: The empirical constants and statistical errors for different models for years 20112012 (optimal values are bold-faced).

\begin{tabular}{|c|c|c|c|c|c|c|c|c|c|}
\hline \multirow[t]{2}{*}{ Year } & \multirow[b]{2}{*}{ Model } & \multicolumn{4}{|c|}{ Statistical Errors } & \multicolumn{4}{|c|}{ Empirical constants } \\
\hline & & $\begin{array}{l}\text { RMSE } \\
\left(\mathrm{MJ} / \mathrm{m}^{2} / \text { day }\right)\end{array}$ & $\begin{array}{l}\mathrm{MBE} \\
\left(\mathrm{MJ} / \mathrm{m}^{2} / \text { day }\right)\end{array}$ & $\begin{array}{l}\text { MPE } \\
(\%)\end{array}$ & $\mathrm{R}^{2}$ & $\mathrm{a}$ & $\mathrm{b}$ & $\mathrm{c}$ & $\mathrm{d}$ \\
\hline \multirow[t]{6}{*}{2011} & M1 & 2.329 & -0.025 & -2.388 & 0.651 & 0.40 & 0.12 & & \\
\hline & M2 & 2.327 & -0.024 & -2.383 & 0.651 & 0.42 & 0.02 & 0.09 & \\
\hline & M3 & 2.325 & -0.023 & -2.383 & 0.652 & 0.41 & 0.10 & -0.08 & 0.11 \\
\hline & M4 & 2.354 & -0.205 & -1.206 & 0.643 & 0.49 & 0.09 & & \\
\hline & M5 & 2.270 & 0.060 & -2.240 & 0.669 & 0.61 & -0.001 & & \\
\hline & M6 & 2.250 & 0.039 & -2.198 & 0.675 & 0.55 & 0.06 & -0.002 & \\
\hline \multirow[t]{6}{*}{2012} & M1 & 2.062 & -0.078 & -2.083 & 0.732 & 0.38 & 0.09 & & \\
\hline & M2 & 2.060 & -0.076 & -2.073 & 0.732 & 0.41 & -0.02 & 0.10 & \\
\hline & M3 & 2.059 & -0.077 & -2.072 & 0.732 & 0.427 & -0.159 & 0.400 & -0.189 \\
\hline & M4 & 2.088 & -0.227 & -1.071 & 0.725 & 0.46 & 0.08 & & \\
\hline & M5 & 2.060 & -0.011 & -2.040 & 0.733 & 0.52 & -0.001 & & \\
\hline & M6 & 2.038 & -0.023 & -1.992 & 0.738 & 0.46 & 0.06 & -0.001 & \\
\hline
\end{tabular}
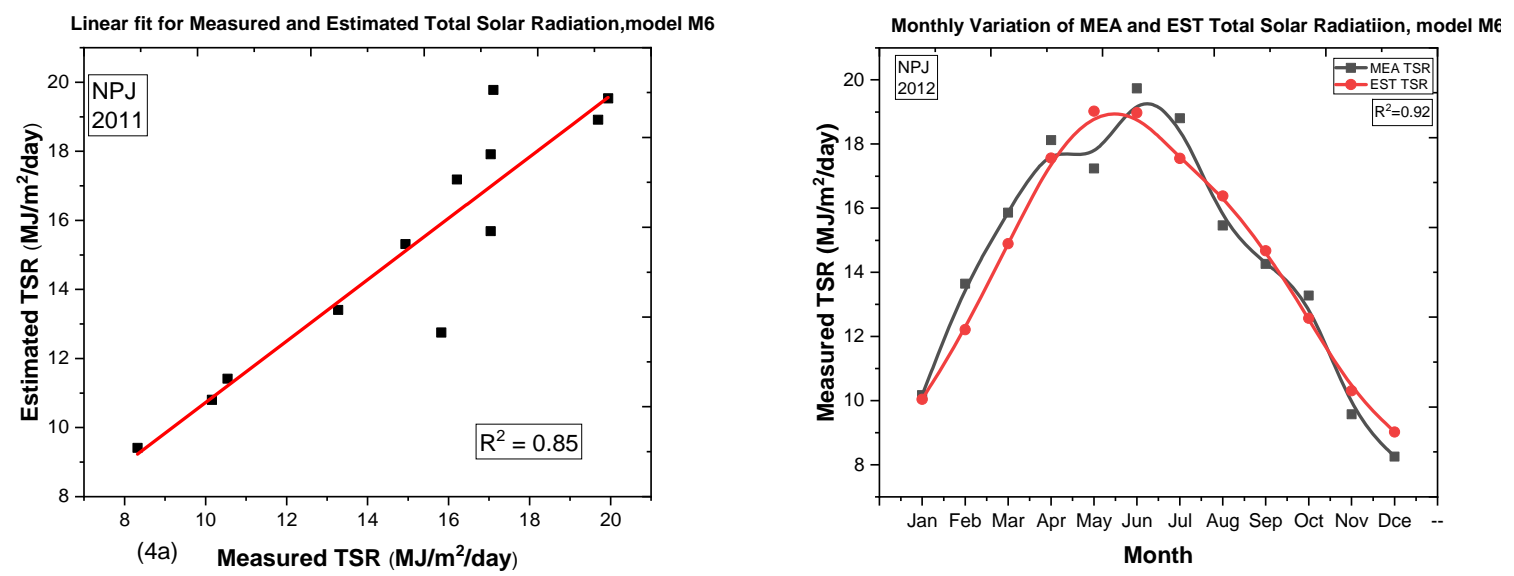

Fig. 4(a), (b): Comparison ofmonthly Measured and Estimated TSR at Nepalgunj in year 2011and 2012 
The plot for monthly measured and estimated total solar radiation is traced in Figure 4 and 5. It is seen that the coefficient of determination for used models are above $85 \%$ and $92 \%$ for year 2011 and 2012 respectively in model M6. Figure shows that there is a remarkable agreement between the measured and estimated values of total solar radiation because most of the data are closer to the trend line and the value of $\mathrm{R}^{2}$ is $92 \%$.
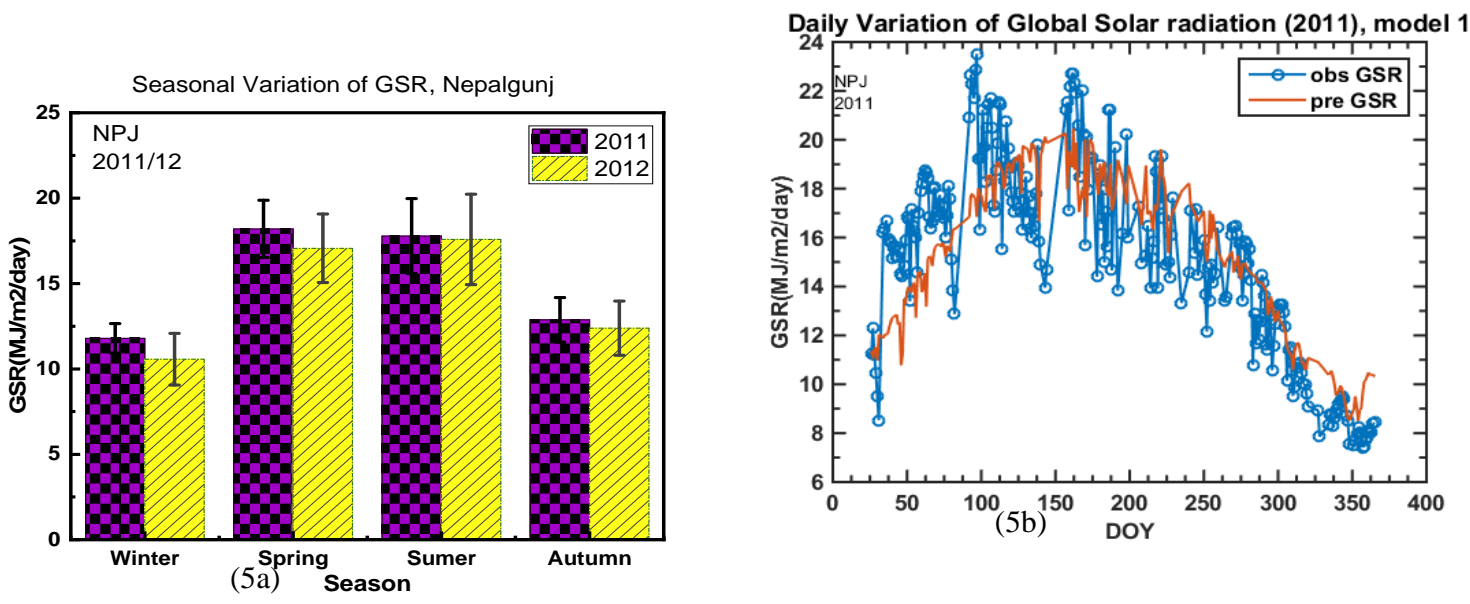

Fig.5: (a) Seasonal variation and (b) Daily Variation of Total Solar radiation for Nepalgunj

The seasonal variation of TSR for Nepalgunj is shown in Fig.5(a) for year 2011 and 2012. In this region, the maximum and minimum amount of TSR are obtained in spring and winter respectively which is similar as in Dang. High value of TSRin spring is attributed due to less solar zenith angle, less cloud and less rainfall. The diurnal variation of TSR varies due to inclination, solar zenith angle, change in season and local weather condition. Fig. 5(b) shows that the daily variation of total solar radiation at measurement site. The maximum solar radiation was found to be $23.51 \mathrm{MJ} / \mathrm{m}^{2} /$ dayon 7 th April and minimum solar radiationfound $2.03 \mathrm{MJ} / \mathrm{m}^{2} /$ dayon $20^{\text {th }}$ January, 2011.The annual average measured value of TSR was $(12.9 \pm 0.25) \mathrm{MJ} / \mathrm{m}^{2} /$ day which is sufficient to generate the solar energy.
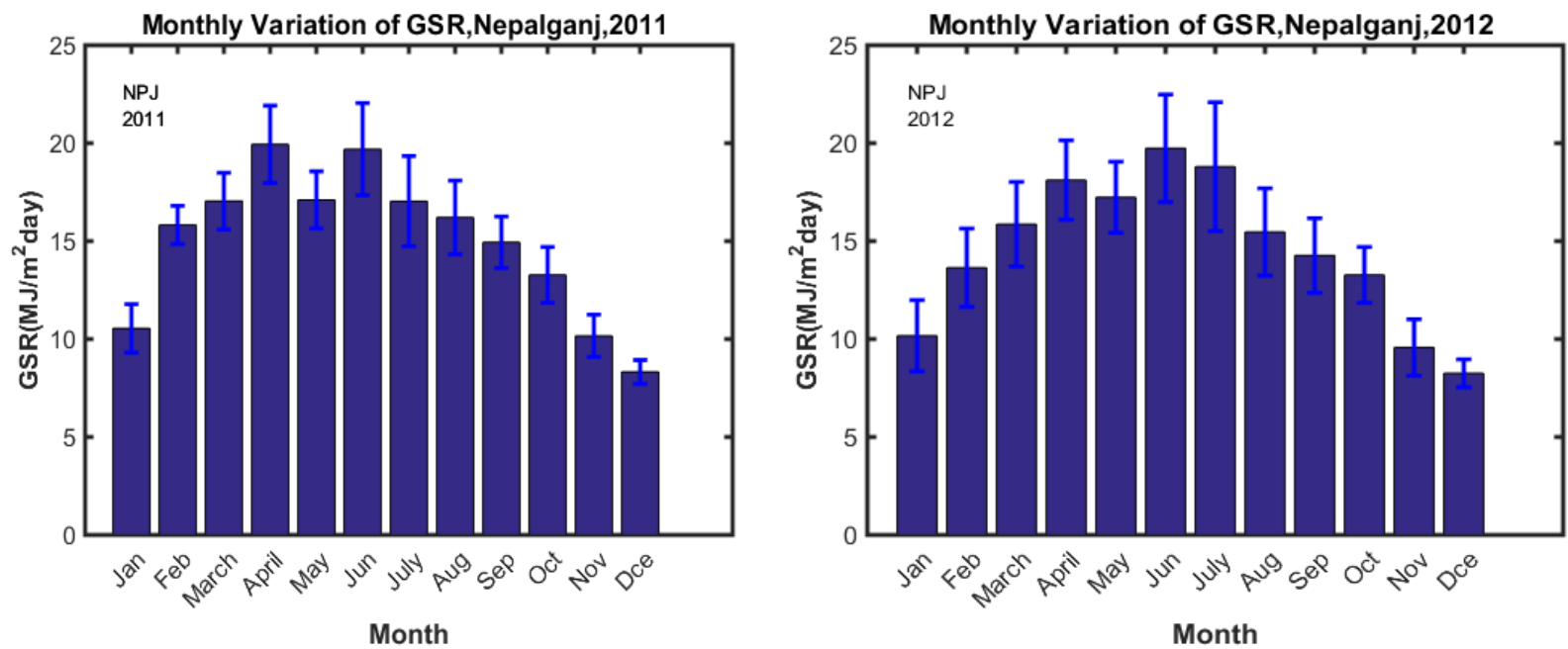
Fig.6(a) and (b): Daily Variation of Total Solar radiation for Nepalgunj

Fig. 6(a), (b) gives the monthly variation of TSR for year 2011 and 2012.Above graph shows the value of total solar radiation received is maximum in the month of April and June. It is mainly due to less cloud, no wind, less rainfall and less solar zenith angle. However, the normal trend deviates for the months of July and August for the studied sites due to the fact that they are rainy reasons for the site and maximum rainfall of the year occurs in these months. In May, due to pre-monsoon, radiation is lower due to cloudy sky. In monsoon season the average rainfall is about $70 \%$ to $90 \%$ of whole year and remaining month's remains almost dry (Nayava et al., 2009).
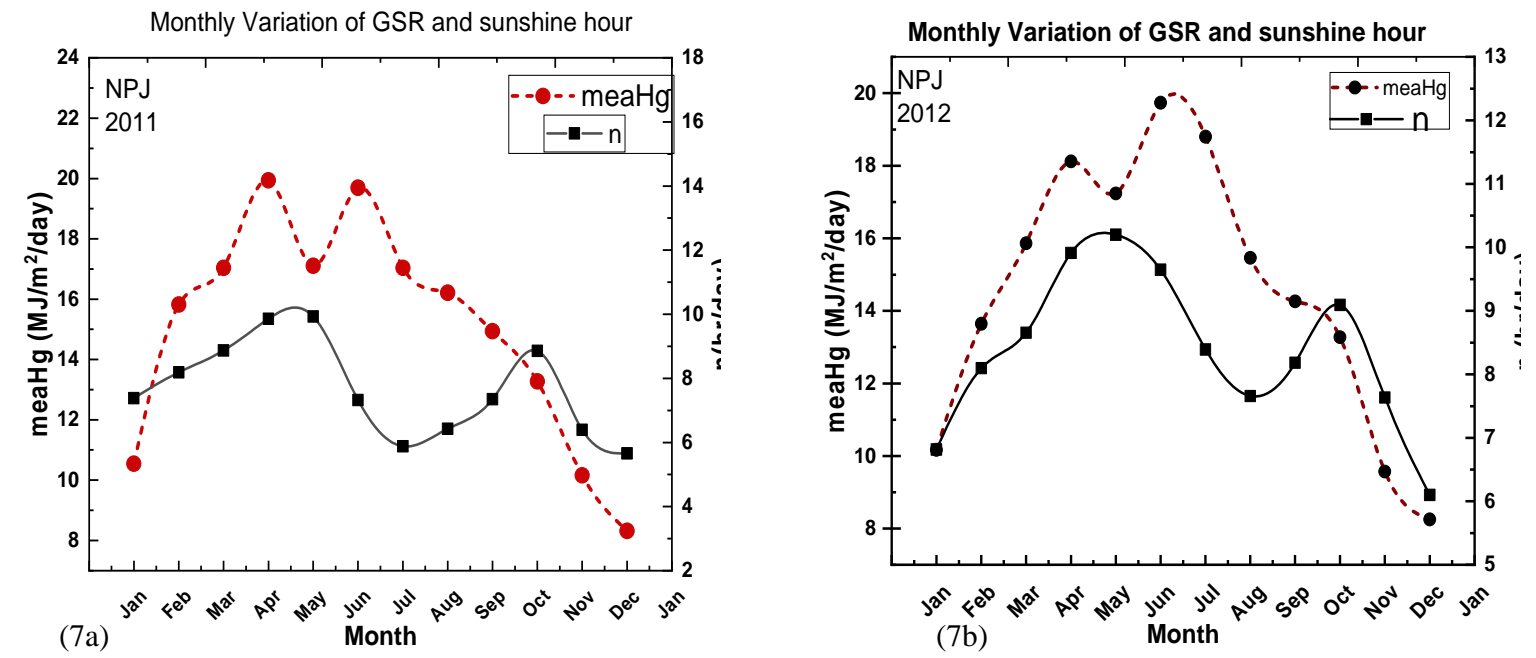

Fig.7(a) and (b): Monthly Variation of Total Solar radiation, Sunshine Hour for Nepalgunj Solar Radiation is directly related with sunshine hour. It is clearly shown in Fig 7(a) and \& 7(b). It also shows that there is strong correlation in between sunshine hour and measured TSR. It is confirmed that the sunshine duration varies from season to season due to the rotation of earth and local weather conditions. The sunshine hour is directly affects the result of Total solar radiation. From above figure it shows that there is strong agreement between sunshine hour and TSRhowever there is reverse nature in average relative humidity with TSR. Sunshine hour and TSRgradually increases from December to April and sharply decrease due to high frequency of rain fall as well as cloudy days in May, June, July and August and till September. The sunshine duration of radiation and intensity also play the 
vital role for the radiation received at different year. There is high decrease of sunshine duration in June, July and August due to cloud cover and high rainfall.
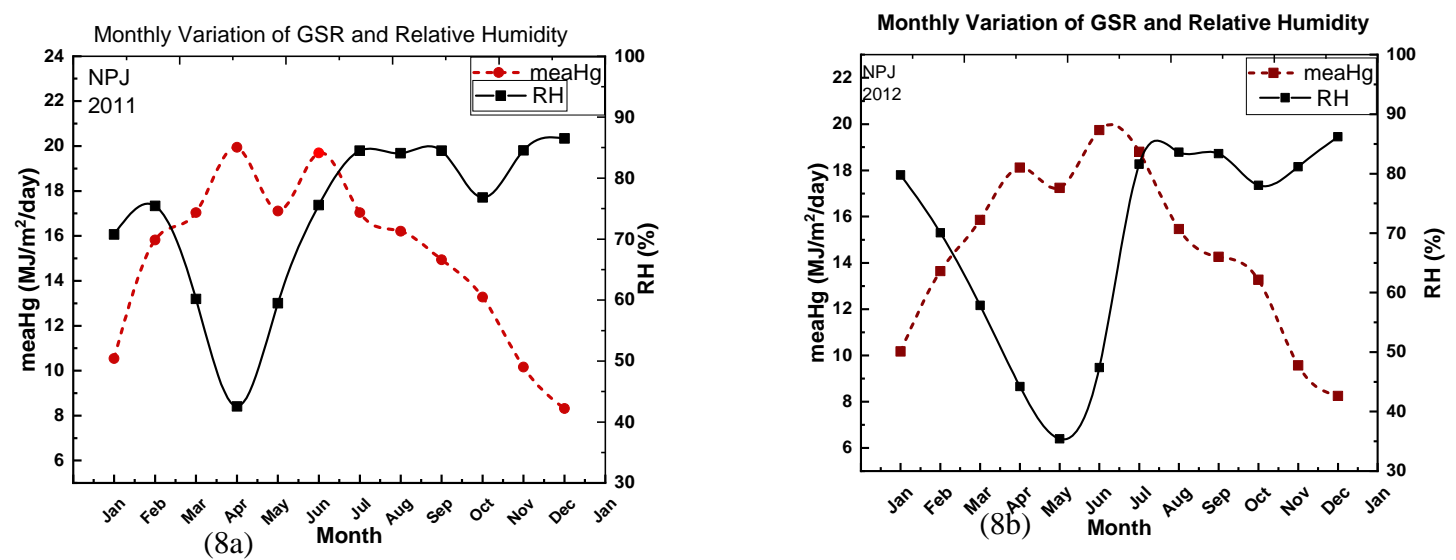

Fig.8(a) and (b):Monthly Variation of Total Solar radiation and Relative Humidity for Nepalgunj fo year 2011 and 2012

The TSR decreases with increases in relative humidity because humidity absorbs the TSR. It is clearly shown in Fig. 8(a) and 8(b). In spring season, dry season, humidity is low and radiation is high .In rainy season radiation is decrease with increase of humidity.

\section{Conclusion}

The maximum and minimum values of monthly average global solar radiation are found $19.73 \pm 2.74 \mathrm{MJ} / \mathrm{m}^{2} /$ day and $8.25 \pm 0.71 \mathrm{MJ} / \mathrm{m}^{2} /$ day in June and December for year 2011 and $19.9 \pm 1.97 \mathrm{MJ} / \mathrm{m}^{2} /$ day and $8.31 \pm 0.6 \mathrm{MJ} / \mathrm{m}^{2} /$ day in April and December for year 2012 respectively. The annual average global Solar Radiation is about $12.74 \pm 4.90 \mathrm{MJ} / \mathrm{m}^{2} / \mathrm{day}$ ) is found which is significant amountto operate numerous devices .The overall performance of parameters RMSE, MBE, MPE and $\mathrm{R}^{2}$ are found 2.04, 0.23, 1.992 and 0.74 are found respectively in the model M6(Swarthman-Oguniade model).These statistical errors showed that this research work is meaningful for the estimation of global solar radiation on the basis of sunshine hour and relative humidity. It indicates that the estimated values of global solar radiation can be very efficiently used to compensate for the energy deficit in the country. It concluded that the availability of global solar radiation is very encouraging from application point of view. At the end, the predicting regression coefficients could be employed for the estimation of global solar radiation at the similar climatic locations of Nepal. 


\section{Acknowledgement}

Authors sincerely express deep gratitude to Department of Hydrology and Meteorology (DHM), Government of Nepal for providing relevant meteorological data. Authors would like to give special thanks to R. Bachchan and faculty members and staffs of Dept. of Physics, Patan Multiple Campus, TU, Nepal and faculty members of Applied Sciences, Chemical Engineering IOE, Pulchowk Campus, TU. We would like to thank Nepal Academy of Science and Technology (NAST) for providing financial support to forward the research work.

\section{References}

Angstrom, A. (1924). Solar and terrestrial radiation. report to the international commission for solar research on actinometric investigations of solar and atmospheric radiation.

Quarterly Journal of the Royal Meteorological Society, 50(210), 121-126.

Babatunde, E., \& Aro, T. (1990). Characteristics variation of total (global) solar radiation at ilorin. Nigeria. Nig. J. of Solar Energy, 9, 157-173.

Besharat, F., Dehghan, A. A., \& Faghih, A. R. (2013). Empirical models for estimating global solar radiation: A review and case study. Renewable and Sustainable Energy Reviews, 21, 798-821.

Duffie, J. A., \& Beckman, W. A. (1991). Solar engineering of thermal processes. 2nd edition. John Wiley and Sons, NewYork NY.

Genwa, K., \& Anju, C. (2012). Optimum efficiency of photogalvanic cell for solar energy conversion and storage containing brilliant black pn-ammonium lauryl sulphate-edta system. Research Journal of Recent Sciences, 2277, 2502.

Instruction manual [Computer software manual]. (2008). http://www.kippzonen.com. Delftechpark 36, 2628 XH Delft, The Netherlands.

Iqbal, M. (1979). Study of canadian diffuse and total solar radiation data. i. monthly average daily horizontal radiation. Sol. Energy;(United States), 22(1).

Iqbal, M. (1983). An introduction to solar radiation. Academic Press.

Klein, S. A. (1977, January). Calculation of monthly average insolation on tilted surfaces. Solar Energy, 19(4), 325-329. doi: 10.1016/0038-092X(77)90001-9

Li, H., Ma, W., Lian, Y., \& Wang, X. (2010). Estimating daily global solar radiation by day of year in china. Applied Energy, 87(10), 3011-3017.

Nayava, J. L., Singh, R., \& Bhatta, M. R. (2009). Impact of climate, climate change and modern technology on wheat production in nepal: A case study at bhairahawa. Journal of Hydrology and Meteorology, 6(1), 1-14.

Okundamiya, M. S., Emagbetere, J. O., \& Ogujor, E. A. (2016). Evaluation of various global solar radiation models for nigeria. International Journal of Green Energy, 13(5), 505-512. 
Poudyal, K. N. (2017). Estimation of global solar radiation potential in nepal (Unpublished doctoral dissertation).

Poudyal, K. N., Bhattarai, B. K., Sapkota, B., Kjeldstad, B., \& Daponte, P. (2013). Estimation of the daily global solar radiation; nepal experience. Measurement, 46(6), 1807-1817.

Prescott, J. (1940). Evaporation from a water surface in relation to solar radiation. Trans. Roy. Soc. S. Aust., 46, 114-118.

Sayigh, A. (1977). Estimation of total radiation intensity-universal formula. In Transactionsamerican geophysical union (Vol. 58, pp. 817-817).

Sears, R., Flocchini, R., \& Hatfield, J. (1981). Correlations of total, diffuse and direct solar radiation with the percentage of possible sunshine for davis, california. Solar Energy, 27(4), 357-360.

Sekar, M., Sakthivel, M., Kumar, S., \& Ramesh, C. (2012). Estimation of global solar radiation for chennai. European Journal of Scientific research, 73(3), 415-424.

Stanhill, G. (2003). Through a glass brightly: Some new light on the campbell-stokes sunshine recorder. Weather, 58(1), 3-11.

Wikipedia contributors. (2020a). CampbellâASstokes recorder - Wikipedia, the free encyclopedia.Retrieved from https://en.wikipedia.org/w/index.php?title= Campbell\%E2\%80\%93Stokes_recorder\&oldid=945064673 ([Online; accessed 26March-2020]) Wikipedia contributors. (2020b). Nepalgunj - Wikipedia, the free encyclopedia.

Retrieved from https://en.wikipedia.org/w/index.php?title=epalgunj\&oldid=947149010 ([Online; accessed 26-March-2020]) 